\title{
RBEP
}

\section{Projeto histórico e construção \\ curricular: a experiência social do Fórum do Maciço do Morro da Cruz*}

Jéferson Dantas

\section{Resumo}

Procura discutir a construção curricular nas escolas públicas estaduais e Centros de Educação Infantil (CEIs) pertencentes ao Fórum do Maciço do Morro da Cruz nos últimos quatro anos (2003-2006). Para tanto, teve como ponto de partida a experiência social das comunidades periféricas da cidade de Florianópolis e, posteriormente, a reformulação do currículo dessas unidades de ensino no atendimento ao público escolar em situação de risco. Esta reformulação tem acarretado mudanças no processo de avaliação, compromisso com a eleição direta para diretores e, fundamentalmente, estratégias diferenciadas na formação continuada de educadores.

Palavras-chave: construção curricular; experiência social; Fórum do Maciço do Morro da Cruz.

\section{Abstract \\ Historical project and curricular construction: the social experience of Maciço Morro da Cruz Forum}

The paper tries to discuss the curricular construction in the state public schools and in the Centers of Childhood Education (CEIs) pertaining to Maciço Morro da Cruz Forum in the last 4 years (2003-2006). Therefore, it started

* A construção deste artigo contou com a valiosa interlocução da educadora Justina Inês Sponchiado Mestre em Educação pela PUC/SP. 
${ }^{1}$ A Comissão de Educação, responsável pela articulação, organização proposição dos encaminhamentos das demandas locais na construção de políticas públicas, representa um dos bracos do FMMC, tendo na frente os diretores cação básica e também dos CEIs (Centros de Educação Infantil), assim como outros representantes da equipe pedagógica destas unidades de ensino. Em sua organização mais ampla, o FMMC é legitimado na organização das entidades e/ou associações dos morros, contando com comissões específicas nas áreas de lazer, meio ambiente, segurança, comunicação e trabalho/renda. ${ }^{2}$ Segundo dados da Secretaria Municipal de Habitação e o IPUF (Instituto de Planejamento Urbano de Florianópolis), no Maciço do Morro da Cruz existem 6,6 mil residências em "áreas geográficas de risco, envolvendo 25.940 pessoas". Além dos riscos de desabamento e precárias condições de higiene, crianças e jovens convivem, diariamente com a violência financiada pelo narcotráfico (6,6 mil casas....2006) ${ }^{3}$ A Frente Popular era formada pelos seguintes partidos: Partido dos Trabalhadores (PT), Partido Popular Socialista (PPS), Partido Democrático Trabalhista (PDT), Partido Verde (PV), Partido Comunista do Brasil (PC do B) e Partido Socialista Brasileiro (PSB). No que tangia à forma de governar em Florianópolis, estas agremiações partidárias implementaram uma marca administrativa até então inédita, que passou a ser uma referência em várias capitais e cidades capitaneadas pela Frente Popular: o orçamento participativo.

${ }^{4}$ Vilson Groh é padre e mestre em Educação pela Universidade Federal de Santa Catarina (UFSC). Adepto da Teologia da Libertação, iniciou suas atividades sociais e eclesiásticas na periferia de Florianópolis, em especial na comunidade Mont Serrat, a partir de 1983. Atualmente é reconhecido nacional e internacionalmente pelo seu trabalho junto às comunidades do Maciço Central do Morro da Cruz (Ilha de Santa Catarina) e também nas áreas continentais da Grande Florianópolis. (Araújo, 2004, p. 60). out with the social experience of the peripheral communities in the city of Florianópolis and, later, the curriculum was reformulated in these risk situation education units. This reformulation has caused changes in the evaluation process, commitment with the direct election of directors and, basically, strategies differentiated in the continued teachers formation.

Keywords: curricular construction; social experience; Maciço Morro da Cruz Forum.

\section{Considerações iniciais}

O recorte temporal que originou este artigo corresponde aos últimos quatro anos (2003-2006), tendo em vista que foi nesse período que a Comissão de Educação do Fórum do Maciço do Morro da Cruz (FMMC) ${ }^{1}$ começou a refletir mais detidamente sobre a importância do currículo na inclusão de crianças e jovens em situação de risco. ${ }^{2}$ Por outro lado, a organização mais ampla do FMMC - entendido aqui como movimento social - deu-se em meados da década de 1990, fruto de um processo de discussão gerado durante o governo da Frente Popular ${ }^{3}$ no município de Florianópolis (19931996).

Nas palavras do próprio coordenador do FMMC, Vilson Groh ${ }^{4}$ (2003, p. 9), o espaço pedagógico não se concentra tão-somente no território escolar, mas está encravado nas comunidades periféricas atendidas por estas escolas num processo de redes e parcerias, "onde os territórios vão sendo desguetizados [sic] e ampliam suas relações na construção das políticas públicas, através do fortalecimento dos movimentos comunitários". Entretanto, não é sem tensões e conflitos que estes diferentes espaços de convívio se legitimam e buscam suas próprias identidades. Há uma trama institucional no território escolar que pode ao mesmo tempo promover uma formação emancipatória de diferentes sujeitos históricos como desqualificar suas histórias de vida, naturalizando as desigualdades sociais e ampliando os já assustadores índices de evasão e repetência nos primeiros anos de vida escolar. As unidades de ensino, por serem espaços historicamente institucionalizados, ainda carregam uma marca política/ideológica arraigada ao favoritismo e ao clientelismo, resultado de impasses históricos que ainda forjam determinadas hierarquizações internas, sem conseguir desburocratizar as determinações verticalizadas dos sistemas de ensino (Valle, 1996).

Além dos aspectos supracitados, os últimos anos da década de 1990 no campo educacional brasileiro tornaram-se emblemáticos. Ganhou força o pragmatismo ideológico, e os movimentos sociais mais combativos de décadas anteriores arrefeceram e perderam sua capacidade de intervenção. A lógica do projeto neoliberal, formalizada na aprovação da Lei de Diretrizes e Bases da Educação Nacional em 20 de dezembro de 1996, de cunho privatista, ambígua e lacunar (Saviani, 2000a), também reacomodou as relações entre o poder público e as comunidades locais. Consolidou-se ainda a 
idéia do voluntariado na educação básica e a adaptação funcional dos trabalhadores em educação (polivalência). Em nível regional este contexto se agudiza com a eleição de Esperidião Amin ${ }^{5}$ para o governo do Estado (1999-2002) e de sua cônjuge, Ângela Amin, para a cidade de Florianópolis (1997-2000/ 2001-2004), denotando velhas práticas clientelistas e gestões que governam de costas para as comunidades periféricas.

No que concerne à territorialização do objeto em questão, é importante levantar alguns aspectos históricos que levaram à atual organização populacional periférica de Florianópolis, fundamentalmente a ocupação desordenada dos morros e encostas. A capital catarinense teve toda a sua ocupação urbana realizada de maneira dispersa. Nos primeiros sessenta anos do século 20, Florianópolis conservava o seu ar provincial, e a especulação imobiliária estava longe dos patamares que alcançou principalmente nos anos 70. Foi na gestão do governador Celso Ramos (1961-1965) que se criou o $1^{\circ}$ Plano de Metas do Governo (Plameg), que, entre outras medidas, apontava para a ampliação de quadros técnicos especializados e toda uma reformulação logística que possibilitasse a instituição de bancos, universidades, empresas, etc., em Santa Catarina. Os governos subseqüentes mantiveram a lógica do Desenvolvimento com Segurança, tendo em vista o período da Ditadura Militar, e Florianópolis passou a ter uma robustez administrativa no setor público até então inimaginável (Dantas, 2002). Entretanto, é importante que se considere que, mesmo antes da ascensão dos generais-presidentes ao Poder Executivo, Florianópolis já havia sofrido sensíveis reformulações urbanas durante os primeiros anos republicanos. Cortiços, casas simples de pedreiros, marceneiros e de lavadeiras foram demolidos para dar lugar a praças e prédios públicos, como convém a uma capital. A sanitarização e o embelezamento da cidade seguiam o modelo da capital brasileira, Rio de Janeiro, onde o prefeito-engenheiro Pereira Passos empreendeu uma verdadeira guerra contra os desvalidos que contaminavam a cidade. ${ }^{6} \mathrm{Em}$ Florianópolis, as elites políticas, famílias tradicionais, tinham o claro intento de afastar a leva de homens e mulheres pobres dos passeios públicos, além de recolhimento de crianças órfãs, evitando assim a proliferação da prostituição. As elites políticas florianopolitanas, desta forma, 'permitiram' que este contingente excluído passasse a ocupar o Morro do Antão - antiga denominação do Morro da Cruz -, elevando os patamares de miséria e condições adversas de convívio social (Kupka apud Nascimento, 2003).

Vale destacar, ainda, as intensas práticas migratórias para Florianópolis, que se ampliaram justamente durante o regime militar. O setor econômico primário foi incrementado com a agroindústria e também com a intensa abertura da economia nacional ao capital estrangeiro, através da transferência tecnológica dos países centrais para os países periféricos. Logo, com os investimentos maciços no setor agroindustrial catarinense, iniciou-se um processo crescente de êxodo rural, já que os pequenos agricultores e suas práticas agrícolas consideradas ultrapassadas tinham dificuldade em obter créditos, além de terem de competir com o 'grande capitalista' da área rural. Os dados estatísticos não deixam dúvidas: durante a década de 1960, praticamente $70 \%$ da população produtiva catarinense estavam concentradas no setor rural; já na década de 1980 este índice cai para 40\% (Giese, 1989).

\footnotetext{
${ }^{5}$ Esperidião Amin foi governador de Santa Catarina em outra oportunidade (1982-1986). Aliado das tradicionais cepas oligárquicas que governam o Estado, Amin se constitui atualmente como uma das principais lideranças políticas do Partido Progressista (PP), legenda oriunda da antiga Arena (Aliança Renovadora Nacional) do período da ditadura militar (1964-1985).

${ }^{6} \mathrm{O}$ acontecimento histórico aqui relatado se refere à Revolta da Vacina (1904), denotando a ausência de políticas públicas para os setores excluídos da sociedade civil, além de revelar a face perversa do regime republicano recém-inaugurado no País.
} 
${ }^{7}$ Atualmente, as escolas públicas estaduais que atendem diretamente às comunidades pertencentes ao Fórum do Maciço do Morro da Cruz são as seguintes: Lúcia do Livramento Mayvorne (comunidade Mont Serrat), Jurema Cavalazzi (comunidade do Morro da Queimada), Celso Ramos (comunidade Morro do Mocotó), Lauro Müller (bairros centrais e comunidades de morros adjacentes), Henrique Stodieck (bairros centrais e comunidades de morros adjacentes), Hilda Teodoro Vieira (comunidade do Morro da Penitenciária), Silveira de Souza (bairros centrais e comunidades de morros adjacentes), Antonieta de Barros (bairros centrais e comunidades de morros adjacentes), Padre Anchieta (Comunidade do Morro do Horácio) e Escola Jovem de Canasvieiras, recentemente incorporada ao Fórum. Há ainda quatro CEIs (Centros de Educação Infantil) mantidos pelo poder público estadual que compõem a Comissão de Educação do Fórum do Maciço. São eles: Cristo Redentor (Morro da Mariquinha), Anjo da Guarda, Nossa Senhora de Lourdes e Mont Serrat (comunidade do Mont Serrat).

${ }^{8}$ Conforme publicado num jornal de grande circulação em Santa Catarina, a Secretaria de Educação pretende convidar pesquisadores da Universidade Federal de Santa Catarina (UFSC) e da Universidade do Estado de Santa Catarina (Udesc) para a elaboração de um 'estudo científico' sobre as escolas que compõem o Fórum do Maciço do Morro da Cruz. De acordo com a Secretária de Educação, Elisabete Anderle, é importante que se tenha uma pesquisa quantitativa sobre os avanços e deficiências das escolas do FMMC e não somente avaliações empíricas. Significaria ainda avaliar a experiência da eleição direta para a escolha de diretores, prática já realizada nas escolas do Fórum, com previsão de se transformar em projeto de lei a partir de 2007 (Viana, 2006).

${ }^{9}$ A Comissão de Educação do FMMC se reúne quinzenalmente, tendo como sede dos encontros as próprias unidades de ensino pertencentes ao Fórum. Uma vez por mês ocorre o Fórum ampliado, com a participação de todas as comissões e, fundamentalmente, a presença de lideranças comunitárias.

${ }^{10}$ Podemos afirmar que o 'laboratório' de organização do Fórum do Maciço do Morro da Cruz começou na comunidade Mont Serrat - incluindo aí as idéias subjacentes à estruturação de comissões e lideranças -, tendo em vista que Vilson Groh estabeleceu residência nesse local.

${ }^{11}$ O Plano Diretor Participativo ainda está em curso na cidade de Florianópolis, conforme prevê o estatuto das cidades em âmbito nacional. Cf. Dantas (2006).
Segundo dados do IBGE, em 2000, 21,3\% dos catarinenses permaneciam no campo, o que posicionava Santa Catarina como o terceiro estado do País com o maior índice de êxodo rural e o primeiro colocado na Região Sul (Kluwe, 2006).

Não sem razão, os conflitos no campo contra a concentração de terras nas mãos de latifundiários vão gerar, anos mais tarde, o movimento dos trabalhadores rurais sem-terra (MST). É somente com este quadro contextual, pintado aqui em rápidas pinceladas, que podemos compreender a importância de um movimento social como o Fórum do Maciço do Morro da Cruz.

Atualmente, as dez escolas de educação básica e os quatro CEIs que atendem às comunidades empobrecidas dos morros de Florianópolis ${ }^{7}$ enfrentam demandas pontuais em relação ao sistema estadual de ensino, principalmente no que concerne à eleição direta de diretores e a uma política salarial que atenda às necessidades mais objetivas dos(as) educadores(as). ${ }^{8}$ Desta maneira, pensar em uma construção curricular diferenciada para crianças e jovens em situação de risco torna-se, além de uma necessidade premente, um desafio constante para os(as) que acreditam no fortalecimento e na interatividade entre as comunidades escolar e local.

\section{A Comissão de Educação do FMMC $^{9}$ como mediadora na construção do currículo}

O Fórum do Maciço do Morro da Cruz (FMMC) passou a se organizar de maneira mais efetiva a partir de 2000, tendo em vista as crescentes demandas estruturais das comunidades dos morros e encostas atendidas por determinadas escolas públicas estaduais de Florianópolis. ${ }^{10}$ Através do Fórum tem sido possível manter projetos de extensão com os mais diversos cursos da Universidade Federal de Santa Catarina, destacando-se Serviço Social, Arquitetura, Biblioteconomia, Pedagogia e Geografia. Busca-se, portanto, amparo técnico e logístico para a formulação de um Plano Diretor ${ }^{11}$ que atenda às demandas da comunidade, bem como para projetos que visem à educação ambiental e à geração de renda.

Etimologicamente, o termo maciço corresponde ao recorte geomorfológico irregular no qual se concentra uma população plural em termos geográficos e sociais (econômicos, políticos e culturais) numa sucessão de comunidades com identidades próprias. De acordo com Araújo (2004, p. 91),

O substrato geológico-geomorfológico sobre o qual se instalou o Maciço Central é composto por três unidades litológicas: grandes riolitos e diques de diabásio, que deram origem a solos com espessuras variadas sobre os quais se desenvolveu uma vegetação classificada como Floresta Ombrófila Densa (Mata Atlântica). [...], com o desmatamento da Mata Atlântica nesta região aceleraram-se os processos erosivos. Sendo assim, é arriscada a ocupação dessas encostas para habitação, visto que a criação de patamares em terrenos íngremes, associados à falta de infraestrutura básica que coloca os efluentes advindos das habitações em contato direto com o solo, têm como conseqüência o aumento da plasticidade dos argilo-minerais, caracterizando-as como áreas de risco. 
Neste sentido, não raro as escolas de educação básica localizadas nas proximidades dos morros recebem um público multifacetado, resultado de práticas migratórias inter/intra-regionais, principalmente das áreas rurais de Santa Catarina. Logo, a identidade dos moradores dos morros e encostas de Florianópolis está intimamente associada aos problemas da produção da vida material da população rural, visto que muitos dos seus habitantes são imigrantes expropriados de suas terras (Araújo, 2004, p. 78).

Logo, estabelecer critérios avaliativos no corpo social das unidades de ensino referenciadas e um currículo integrado requer a compreensão mais ampla dessas diferentes realidades comunitárias, uma realidade de praticamente 30 mil pessoas comprimidas nas encostas e que convivem diariamente com o medo, a insegurança e a violência do narcotráfico. Para Vilson Groh, embora não seja possível estabelecer quadro comparativo entre a realidade de Florianópolis e Rio de Janeiro,

[...] dá [pra] fazer quadros quando [...] tens um diagnóstico de 13,5 mil jovens destituídos de direito, jovens que não têm [...] certidão de nascimento, nunca foram à escola [...]. E ainda um percentual de jovens em conflito com a lei. [...] Se o governo não entrar agora maciçamente, eu diria que em dez anos nós teremos aqui um segundo Rio de Janeiro. Estamos dizendo isso desde 1980. Precisamos de projetos. Não é dar esmola. Ninguém quer comida pela comida. O tráfico é uma coisa transnacionalizada hoje em dia, um quarto poder (Vargas, 2006, p. 8-9).

Entendemos que nenhum currículo será debatido, desenvolvido e internalizado pelos educadores que atendem estas comunidades se não houver, por parte deles e sobretudo em tal contexto, a compreensão de que o tempo e o espaço escolares precisam ser redimensionados. Afirmar isso é também admitir que não é possível uma intervenção qualitativa, por parte das unidades de ensino, apenas com o esforço e a boa vontade de sua equipe pedagógica. E que, portanto, é fundamental desmontar o discurso do poder público, que tem depositado um encargo social de extrema responsabilidade aos educadores, conforme análise de Saviani (2000b, p. 2):

[...], tornou-se freqüente, ganhando mesmo o status de slogan, a afirmação de que a saída está na educação, sendo ela a solução para os diversos problemas que afligem a humanidade, desde a violência, passando pelo desemprego, a miséria, a exclusão social, até as agressões ao meio ambiente. Parece ressurgir, assim, a visão ingênua que inverte os termos do problema, tomando o determinante pelo determinado e viceversa. Com isso, a educação de elemento socialmente determinado passa a ser veiculada como determinante das relações sociais, sendo capaz, em conseqüência, de modificá-la pela força de seu intrínseco poder.

A diminuição do Estado, a adaptabilidade funcional e flexível do trabalhador em educação, a prática do voluntariado, sacudiram sobremaneira os alicerces das principais bandeiras educacionais no Brasil pós-ditadura militar (1964-1985). Assim, os encaminhamentos pedagógicos - que são acima de tudo práticas sociais - devem estar voltados a uma investigação permanente de como se opera a exclusão social e quais mecanismos são necessários nas escolas para se evitar o reforço desta exclusão. Para tanto, o currículo escolar teria de romper suas fronteiras ou áreas disciplinares, 
[...] baseada na interpretação da realidade, orientada para o estabelecimento de relações entre a vida dos alunos e professores e o conhecimento disciplinar e transdisciplinar (que não costuma coincidir com o das matérias escolares) vão elaborando. Tudo isso para favorecer o desenvolvimento de estratégias de indagação, interpretação e apresentação do processo seguido ao estudar um tema ou um problema que, por sua complexidade, favorece o melhor conhecimento dos alunos e dos docentes de si mesmos e do mundo em que vivem (Hernández, 1998, p. 39).

O educador espanhol Fernando Hernández reforça que a dimensão de um currículo transdisciplinar não é tarefa pragmática, com um ponto final. Antes, porém, estabelece novas e crescentes problematizações, que vão desde as mudanças pontuais na organização espaço-temporal da escola, o currículo por disciplinas, as expectativas das famílias, atitudes profissionais dos estudantes, até a sensibilidade do poder público e dos meios de comunicação.

Para o educador estadunidense Michael Apple, as mudanças curriculares só podem ocorrer de maneira efetiva com a boa formação inicial dos educadores. Isto significa não seguir à risca o que recomendam os manuais didáticos, muito menos basear-se tão-somente em modelos curriculares oficiais. Um outro dado importante que precisa ser problematizado é que, em Santa Catarina, praticamente 90\% do magistério no Ensino Fundamental é formado pelo sexo feminino. A feminização do magistério e, por conseguinte, as lideranças que hoje estão na frente das escolas pertencentes ao FMMC correspondem exatamente à participação decisiva das mulheres. Quando Apple nos alerta de que as educadoras estadunidenses - e as brasileiras também se incluem aí - trabalham horas a fio durante o dia, em condições adversas, além do desgaste emocional, torna-se fundamental acrescentar que o seu trabalho não se esgota ali; continua no espaço doméstico, em função dos filhos, do marido e de tarefas alheias ao ofício pedagógico (Linhares, Garcia, 1996, p. 102-103). Exigir dessa profissional um equilíbrio psíquico permanente, sem que ela se depare com momentos em que exclui um(a) determinado(a) aluno(a) ou que tenha um ceticismo exacerbado em relação às mudanças estruturais na educação, é no mínimo contraditório.

Todavia, construir um currículo escolar que consiga atender a expectativas tão variáveis também não é um exercício simples. Vilson Groh, coordenador do FMMC, bastante influenciado pela pedagogia problematizadora de Paulo Freire, sugeriu nas reuniões da Comissão de Educação do FMMC que cada escola se reunisse com sua comunidade local para definir que eixos temáticos precisariam ser discutidos e operacionalizados em sua unidade de ensino. É importante lembrar que a trajetória sacerdotal de Groh está fortemente vinculada ao pensamento social cristão, fundamentalmente aquela associada à teologia da libertação. Ao reunir os elementos teóricos e metodológicos da pedagogia problematizadora de Freire, Groh assume com a comissão de educação do FMMC o compromisso de se iniciar um modelo curricular que lide com a pesquisa, temas geradores (eixos temáticos), problematização (relação dialógica horizontal), conscientização política e ação social (Ghiraldelli Jr., 1994, p. 124-125). Neste sentido, grosso modo, poderíamos classificar as teorias do currículo em três dimensões conceituais: 
1) as teorias tradicionais; 2) as teorias críticas; e 3) as teorias pós-críticas (Silva, 2003, p. 17). A discussão do currículo no FMMC estaria assim mais próxima das teorias críticas, i.e., de elementos conceituais que lidam mais diretamente com a ideologia, relações de poder, capitalismo, conscientização, currículo oculto, resistência, emancipação, luta de classes e relações sociais de produção.

Os eixos temáticos foram construídos e definidos na Comissão de Educação e nos encontros de formação docente do FMMC. Estes encontros de formação continuada ocorriam e ocorrem uma vez por mês, totalizando nove encontros e 40 horas de efetivo trabalho pedagógico. Os temas debatidos são sugeridos pela Comissão de Educação e mediados pelas unidades de ensino pertencentes ao FMMC. Apenas para citar um exemplo, no ano de 2004 os educadores apostaram em oficinas até então inéditas, tais como educação biocêntrica, expressão corporal, educação multirracial, educação ambiental e "contação" de histórias. No que diz respeito às diretrizes de intervenção curricular, foram elaborados nove eixos, a saber: 1) Violência; 2) Sabor e Saber (merenda sem agrotóxico); 3) Sexualidade; 4) Meio Ambiente; 5) Comunicação; 6) Arte-Educação; 7) Informática; 8) Bibliotecas integradas; 9) Avaliação escolar. Estes eixos estariam transversalizando os currículos das comunidades atendidas pelas escolas do FMMC, objetivando encaminhamentos comuns e, sobretudo, problematizações consistentes relacionadas com o entorno social dos educandos. Tentava-se estruturar, ainda que de forma incipiente, um currículo comum às escolas do FMMC, alicerçado nos problemas mais imediatos das comunidades locais. Entretanto, nem sempre o entendimento dos(as) educadores(as) sobre os eixos temáticos foi realizado de forma coerente. Para grande parte desses educadores, os eixos temáticos se assemelhavam aos temas transversais dos Parâmetros Curriculares Nacionais (PCNs), portanto, desvinculados das disciplinas curriculares. Por outro lado, havia uma outra compreensão de que se teria de abandonar as disciplinas curriculares e adotar os eixos temáticos como novas áreas disciplinares, dilema que até hoje não se dirimiu. Em determinados casos, algumas escolas do FMMC simplesmente desconsideraram a importância dos eixos temáticos na reformulação de seus currículos.

Foi sobretudo no segundo semestre de 2003 que a Comissão de Educação iniciou as primeiras leituras referentes à importância do currículo escolar. Elaboramos um primeiro ensaio das implicações do currículo no processo de inclusão de jovens em situação de risco, mediado teoricamente pela pedagogia de projetos do educador espanhol Fernando Hernández. O documento foi entregue aos diretores das escolas pertencentes à Comissão de Educação do Fórum, ao coordenador e ao secretário-executivo do FMMC - Vilson Groh e Danilo Ledra, respectivamente. ${ }^{12}$

Os debates referentes ao texto foram bastante tímidos nas escolas do FMMC. Apenas uma delas promoveu a discussão dos principais pressupostos contidos neste primeiro ensaio. ${ }^{13}$ A diretora dessa escola, uma das articuladoras do referido Fórum, além de convocar todos os seus educadores para a reunião, solicitou que cada um(a) fizesse uma breve reflexão

\footnotetext{
${ }^{12}$ Professor Danilo Ledra - mestre em Educação pela UFSC - estava, na oportunidade, licenciado pela Secretaria de Estado da Educação para exercer a função de secretárioexecutivo do Fórum do Maciço do Morro da Cruz. Tal situação gerou sucessivas reuniões com a Secretaria de Educação e a Gerência Regional de Educação (Gerei), uma vez que esta função pedagógica não é prevista pelo sistema de ensino de Santa Catarina.

${ }^{13} \mathrm{O}$ encontro ocorreu no dia $19 \mathrm{de}$ fevereiro de 2004, no período noturno, envolvendo boa parte dos educadores da escola.
} 
sobre o que entendeu do texto (oralmente ou por escrito). O feedback dos educadores indicou a necessidade de se ampliar o debate para as demais unidades de ensino. Um docente da área de Filosofia, que teve o cuidado de entregar sua reflexão por escrito, indagava: a) Será que mudando o modelo da escola (a partir da grade curricular), mudamos o modelo de educação, de pedagogia, de práticas escolares problemáticas? b) Será que podemos nos distanciar de situações que vão além de nossas possibilidades efetivas enquanto educadores? Sugeria também que os eixos temáticos propostos não eram simplesmente temas transversais e tampouco eram disciplinas curriculares. Serviam, isso sim, como eixos norteadores na constituição do Projeto Político Pedagógico e fundamentação teórica para as reivindicações de políticas públicas educacionais. Em suas considerações finais, o professor afirmava que o coletivo precisava "dar a cara", sair de suas tocas e contemplar a luz no horizonte, tal a alegoria da caverna de Platão; e, ao sair da caverna, a possibilidade de se vislumbrar o real, enfrentando a luz dolorosa do conhecimento, teríamos condições objetivas de enfrentar as dificuldades inerentes à prática pedagógica e transformá-la.

No decorrer de 2004, porém, a principal preocupação estratégica do FMMC foi a discussão da identidade das escolas participantes da Comissão de Educação do Fórum, gerando debates por vezes acalorados e, inclusive, em determinadas situações, um clima de "competitividade" entre as referidas unidades de ensino. Na ata do encontro do dia 23 de agosto de 2004, redigida pelo professor Danilo Ledra, algumas questões foram lançadas para a Comissão de Educação: 1) O que nos mantém unidos? 2) Em que somos iguais? 3) Em que queremos/desejamos ser iguais? 4) Quais princípios devem nortear nossas práticas? Para o próprio secretário-executivo do Fórum, a Comissão de Educação não representava um grupo coeso, articulado, unido. Havia muitas divergências, resultando até mesmo em intrigas. Essas intrigas eram fomentadas por alguma competição sutil entre as escolas e suas respectivas direções ou coordenações pedagógicas e também cotidianamente entre os professores. Sugeria então que cada escola discutisse e encaminhasse o que já havia sido incorporado nas suas práticas pedagógicas - e, portanto, em seu currículo -, sobretudo no que diz respeito aos temas meio ambiente, violência, avaliação, sexualidade, alimentação, informática, arte-educação, biblioteca e educação multirracial, aproximando escolas e comunidades (FMMC, 2004).

Argumentei que precisávamos "ser iguais" durante os conflitos políticos com o aparato estatal, reforçando e registrando nossas histórias de luta, operacionalizando a materialidade de nossos projetos pedagógicos e dando visibilidade às nossas atividades culturais (música, cinema, rádio-escola, etc.). Ponderei que as nossas práticas pedagógicas precisariam estar representadas nos encontros mensais de formação do Maciço, pois quando nos vemos, nos espelhamos no outro, temos uma compreensão mais razoável do que desejamos para os nossos estudantes no processo de formação. Lembrando Paulo Freire, concluí que o corpo docente precisava entender o ato pedagógico como um ato amoroso, que demanda intervenção permanente e, sobretudo, investimento psíquico, já que os educadores precisam estar sempre pesquisando e apostando na sua formação continuada (FMMC, 2004). 
No final da ata foram registradas recomendações para a alteração de nossas práticas pedagógicas, conforme transcrição abaixo:

\begin{abstract}
A cultura da representatividade - elegemos e esperamos que o eleito resolva tudo - ainda está muito presente nas escolas, fomos acostumados a transferir as responsabilidades e não assumi-las. É preciso construir um pacto com o grupo, superar esta cultura da transferência de responsabilidades, precisamos superar a "pré-tarefa" - passo para os outros ou os outros dizem o que tenho que fazer - e entrarmos na era da tarefa - assumo compromissos, divido tarefas, assim assumo o coletivamente, o todo. Que tipo de liderança somos? Nossa autoridade é fruto do autoritarismo ou da nossa autoria? Qual visão os professores, os pais, os alunos tem de nós? É preciso denunciar o paternalismo, aproveitando das [sic] contradições que surgem no cotidiano das nossas escolas. É preciso assumir todos juntos nossas ações (FMMC, 2004).
\end{abstract}

Não havia se estabelecido uma 'cultura de grupo' na Comissão de Educação do FMMC, e estávamos também muito distantes de uma organização curricular comum. Os eixos temáticos sequer haviam sido internalizados como práticas pedagógicas, e menos ainda incorporados aos projetos políticos pedagógicos das escolas. Por outro lado, havia toda uma caminhada, além de conquistas que precisavam ser enaltecidas, principalmente a visibilidade que foi sendo dada às comunidades periféricas em Florianópolis. E as avaliações dessa caminhada deveriam considerar os diferentes ritmos de cada unidade escolar. Algumas avançavam mais do que outras, mas nem por isso deixava-se de pensar e encaminhar problemáticas comuns no coletivo da Comissão de Educação. Para Hoffmann (2001, p. 44-45),

[...] não há regras gerais em avaliação. Toda a situação precisa ser analisada em seu contexto. Daí a necessária postura de questionamentos e de discussão conjunta entre os professores. Não se aprende a lidar, em cursos de formação, com as diferenças no ato de educar; não se conhece, de fato, a realidade social e as condições de vida de milhares de alunos das escolas brasileiras; não se tem em cursos de magistério e licenciaturas formação em fonoaudiologia, em psiquiatria, em surdez, em psicomotricidade e tantas outras especializações necessárias ao entendimento das questões de ordem afetiva e intelectual; não se pode ter um conhecimento aprofundado de todas as noções que abrangem um currículo.

Como bem assinala Hoffmann, é impossível avaliar, de forma completa, o alcance do processo educativo escolar e, portanto, do currículo. Os encontros de formação do Maciço também não davam conta das expectativas dos educadores. Havia ali toda uma aprendizagem que precisava ser construída pela Comissão de Educação na organização dos encontros, no convite aos palestrantes e oficineiros e, sobretudo, na queda-de-braço com a Secretaria de Educação, que não reconhecia a nossa formação e não nos auxiliava materialmente. ${ }^{14}$

A ausência de um projeto curricular comum persistia como um 'vácuo', pois as decisões de caráter coletivo numa unidade de ensino necessitam constantemente do diálogo e do embate entre diferentes concepções de aprendizagem. O poder público conservador opera justamente aí, ou seja,

\footnotetext{
${ }^{4}$ Isto foi um dificultador a mais, tendo em vista que à Secretaria de Estado da Educação caberia expedir o certificado com o número de horas estabelecidas nos encontros. A não entrega dos certificados aos professores em determinadas ocasiões também ocasionou a evasão nas datas dos encontros.
} 
na desmobilização das comunidades escolar e local, impondo suas grades curriculares, suas capacitações ${ }^{15}$ desconectadas do entorno social dos educadores e um referencial teórico que até hoje não foi totalmente internalizado por estes trabalhadores em educação. A Proposta Curricular de Santa Catarina (PC/SC), que já tem três versões (1991, 1998 e 2005), ainda representa uma caixa preta para muitos educadores, assim como os Parâmetros Curriculares Nacionais (1998). Em grande medida, os teóricos da educação provenientes dos quadros do PMDB em Santa Catarina - que advogaram para si, em várias unidades da Federação, na década de 1980, a liderança na elaboração curricular das escolas públicas - ainda estão muito distantes das reais necessidades educacionais em nível estrutural (Ghiraldelli Jr., 1994). Sob a égide de um passado histórico comprometido com os ideais de centroesquerda, os governos peemedebistas em Santa Catarina têm promovido um sistemático esvaziamento da discussão política do currículo, posicionando-se contrariamente às ações do FMMC. Daí vir o seguinte questionamento: até que ponto os pressupostos filosóficos e metodológicos da PC/SC ou dos PCNs contribuem nas práticas pedagógicas dos educadores? (Dantas, 2002). Para Alice Casimiro Lopes (2006), já é possível fazer uma avaliação histórica dos efeitos dos PCNs ou de propostas regionais que se aproximam de seu ideário; segundo ela, o Estado tem sido cada vez mais centralizador no que tange às políticas de currículo, atendendo basicamente marcos econômicos globais. Ela, porém, reconhece que muitos estudos do currículo "nem sempre investigam a ação da sociedade civil na política ou as tensões entre sociedade civil e sociedade política", motor de nossa discussão aqui.

Logo, a análise de toda essa problemática, que é multidimensional, precisa ser considerada na interação existente entre as comunidades escolar e local no que concerne às expectativas familiares mais visíveis sobre as práticas pedagógicas desenvolvidas nas escolas de educação básica pertencentes ao FMMC. Afinal, há em média nove mil alunos atendidos pelas escolas e CEIs do Fórum para um universo de 400 trabalhadores em educação, aproximadamente. Deve-se considerar, ainda, que as matrículas de cada escola não correspondem, em determinados casos, aos números reais dos alunos que freqüentam as aulas, tendo em vista a evasão.

Assim, a construção curricular das escolas do FMMC precisa levar em conta como as comunidades locais se formaram e se organizaram nos morros de Florianópolis mediante práticas migratórias, originárias principalmente do meio rural catarinense (meio-oeste, notadamente). A busca por melhores condições de vida vai se realizar num espaço social onde, teoricamente, há maior oportunidade de trabalho, neste caso a capital do Estado. Quando estas famílias chegam a Florianópolis, se deparam com um lugar pouco acolhedor, sobretudo levando-se em conta suas condições de miserabilidade. Há de se destacar ao mesmo tempo a composição étnica dos moradores do Maciço do Morro da Cruz. Apenas para exemplificar, no Mont Serrat, praticamente 80\% dos moradores têm origem afrodescendente (Copette, 2003, p. 60), situação também presente em outras comunidades. 
Com isso, toda a adaptação às condições de vida nesse território de convívio tem de ser absorvida rapidamente, sem qualquer transição menos traumática. Isto significa que o migrante não tem tempo hábil para elaborar conceitualmente suas perdas, que não são apenas materiais, mas fundamentalmente afetivas e sociais:

[...] a migração em si é indicadora não só da sociedade e das relações de força entre regiões, mas também é, fundamentalmente, reveladora dos dilemas e conflitos subjetivos a que está afeito todo aquele que se desloca. O migrante sai de um universo cultural recebido por herança ao nascer em direção a outro em que é confrontado com o que lhe foi dado a priori. Entre o sair e o chegar, ocorre um processo duplo que vai falar das ilusões dos emigrantes ao sofrimento do imigrante que atravessa a fronteira do estabelecido e do desconhecido (Cavalcanti, 2002, p. 148).

Se não tivermos esta percepção de que os que habitam os morros e encostas de Florianópolis se sentem 'estrangeiros' em seu próprio Estado, não teremos um quadro real das subjetividades destas comunidades periféricas. $\mathrm{O}$ marginalizado, o excluído social, já traz consigo toda uma carga pejorativa que lhe dificulta a trajetória em busca de trabalho e uma renda satisfatória. Os mais afetados são os jovens, convivendo com organizações familiares nãonucleares, mergulhadas no trabalho informal, além do narcotráfico; passam a ter um autoconceito extremamente depreciativo, que poderá se agravar durante seu processo de escolarização com o reforço dessa exclusão ou a naturalização das desigualdades sociais. Faz-se necessário compreender como a cultura da violência opera nessas comunidades periféricas, no que diz respeito aos fatores mais concretos - como estes sujeitos produzem a sua vida material - e aos fatores subjetivos. A grande maioria dos jovens matriculados nas escolas de educação básica pertencentes ao FMMC apresenta em suas histórias de vida particularidades comuns, ou seja,

[...] experiências constantes de dor, tristeza, humilhação, abandono e desamparo [levando-os] à negação do sentimento vivido em função dessas experiências. Crianças que são humilhadas, maltratadas, abusadas por adultos, desrespeitadas em sua integridade física e moral acionam um mecanismo de defesa que é a negação do sentimento. Passam a investir todas as suas energias em si próprias para se defenderem e assumem uma atitude agressiva frente à sociedade, em resposta ao que receberam. Revidam à humilhação ou agressão sofrida tentando negar o que sentem com relação ao outro (Vasconcelos, 2002, p. 171).

Em maior ou menor grau, grande parte desses jovens começa a ter um comportamento social intolerável para os mecanismos legais vigentes, representando um perigo real para a sociedade capitalista. As aspirações dessas comunidades excluídas revelam as contradições do modelo capitalista; além das condições básicas de sobrevivência e bombardeadas pelas demandas artificialmente criadas por uma sociedade regida pelo consumo, também passam a desejar o que as classes mais abastadas usufruem e, para isso, utilizam os instrumentos de poder que estão ao seu alcance. A partir do que propõe Vasconcelos, os sujeitos que sofrem de perdas afetivas desde a infância podem, cedo ou tarde, desenvolver determinadas características de 
personalidade que afetam a capacidade de julgar. Isto significa que a vida perde qualquer valor, e todo e qualquer sentimento fica praticamente anestesiado no íntimo desse sujeito. ${ }^{16}$

Como pensar, então, num currículo escolar que atenda às subjetividades dessas comunidades?

Uma das falhas estratégicas que a Comissão de Educação do FMMC cometeu foi a tentativa de estabelecer um currículo comum e, numa perspectiva transdisciplinar, sem dialogar de maneira mais ampla com as comunidades atendidas pelas escolas de educação básica do Fórum. Além disso, é importante destacar que o sistema de ensino oficial não abre mão de suas interferências no campo curricular. Quando lidamos diretamente com práticas discursivas no ambiente escolar, não é possível minimizar aquilo que os sistemas de ensino compreendem ser o que deve ser seguido, aquilo que é mais doutrinário ou pragmático, com todas as relações de força e saberes entrecruzadas. Nas palavras de Michel Foucault (2004, p. 44-45):

O que é afinal um sistema de ensino senão uma ritualização de palavras, senão uma qualificação e uma fixação dos papéis para os sujeitos que falam; senão a constituição de um grupo doutrinário ao menos difuso; senão uma distribuição e uma apropriação do discurso com seus poderes e seus saberes?

Necessariamente, há um embate entre o currículo oficial e aquele que se pretende construir pela sociedade civil. E isto se torna intrincado nos dias de hoje, tendo em vista que os currículos oficiais trazem elementos conceituais, teóricos e metodológicos bastante semelhantes àqueles construídos pelos movimentos sociais do magistério na década de 1980. Nos termos de Corazza (2004), corre-se o risco de hibridismo curricular, e o que era 'alternativo' passa a ser um amálgama difícil de discernir, teoricamente.

Por fim, os elementos subjetivos presentes nessas comunidades específicas (linguagens, brincadeiras, violência) terão de dialogar, necessariamente, com elementos tangíveis presentes no universo escolar. ${ }^{17}$ Logo, os PPPs, manuais didáticos, recursos midiáticos, atas de conselhos de classe, relatórios individuais de estudantes, fichas individuais de avaliação (boletins), encontros pedagógicos, modelos de formação continuada de educadores, estrutura ergonômica dos prédios escolares, acervo da biblioteca da escola, espaço para recreação/práticas desportivas, exercícios dirigidos, etc., precisam ser elevados à condição de fontes primárias para se compreender o currículo em ação, em seus aspectos claramente expressos e naqueles ditos ocultos.

${ }^{16}$ A autora tenta articular em sua explanação as interfaces teóricas e metodológicas entre Sociologia e Psicanálise, chegando a algumas definições bastante significativas para uma possível compreensão de comportamentos forjados nesses contextos.

${ }^{17}$ Por elementos tangíveis, compreendo todos aqueles que produzem e reproduzem conhecimento, interferindo diretamente na prática social dos educadores.

\section{Considerações finais}

Afirmar que as escolas de educação básica do FMMC possuem, atualmente, um currículo comum não corresponde à realidade. Essencialmente, as reformulações das práticas pedagógicas e, conseqüentemente, do currículo de cada unidade de ensino tiveram como ponto de partida os eixos temáticos elencados na Comissão de Educação e trabalhados na formação 
continuada, mensalmente. Várias ações pedagógicas foram encaminhadas neste sentido, das quais podemos destacar: a) merenda escolar sem agrotóxico; b) formação dos agentes da paz; c) avaliação descritiva; d) rádio-escola; e) biblioteca escolar nos moldes acadêmicos; f) mostras permanentes de educação ambiental e o pacto das águas.

No que tange à merenda escolar sem agrotóxico, praticamente todas as unidades de ensino do FMMC passaram a comprar produtos hortifrutigranjeiros provenientes de uma cooperativa de pequenos agricultores da cidade de Santa Rosa de Lima, Santa Catarina. Tínhamos a compreensão de que, ao fazer isso, estávamos também fortalecendo a permanência do homem no campo, evitando as constantes migrações ou o êxodo rural, além de estarmos oferecendo uma alimentação mais saudável para as crianças e os jovens de nossas escolas.

A formação dos 'agentes da paz' não foi uma ação conjunta. Partiu, basicamente, de uma única escola, bastante prejudicada pelos constantes atos de vandalismo ao prédio escolar por parte de jovens estudantes. A direção da referida unidade de ensino estabeleceu parcerias com a iniciativa privada do bairro onde a escola se situa, tendo como principal acordo a geração de empregos ou cursos de línguas estrangeiras e informática para os jovens. A iniciativa privada atendeu ao pedido e passou a ter um papel de destaque no interior da escola, favorecendo a diminuição dos índices de repetência e evasão. Os jovens que mais depredavam a escola passaram a ter função destacada como 'agentes da paz', promovendo eventos, cuidando das crianças nos recreios e obtendo o seu primeiro emprego. Cabe lembrar que a escola fica próxima da penitenciária estadual de Florianópolis (comunidade do Morro da Penitenciária) e que vários pais de alunos estão presos ali. Em 2002 esta escola recebeu o prêmio de escolas inovadoras, concedido pela Unesco (Abramovay, 2003).

O sistema de avaliação foi o que mais rendeu polêmicas e falta de consenso. Determinadas escolas queriam abolir a certificação quantitativa e avaliar o aluno de maneira integral e descritivamente. Porém o sistema estadual de ensino alegava que, em caso de transferência de aluno, as avaliações deveriam ser transformadas em notas. Em muitos casos, a Gerência Regional de Educação chegou a exigir a permanência da avaliação certificativa. Os pais também não compreendiam o rendimento escolar dos seus filhos. Acostumados ao ritual das notas, os pareceres descritivos pareciam 'mascarar' aquilo que, efetivamente, o(a) estudante conseguiu se apropriar conceitualmente. Entretanto, algumas escolas mantiveram a avaliação através de pareceres descritivos, esclarecendo pais e estudantes do que estava sendo avaliado e onde era necessário retomar os estudos. Tentava-se, assim, evitar os rótulos tão comuns daqueles que têm 'notas altas' e dos que têm 'notas baixas', além da prova como único e eficiente instrumento de avaliação. Para tanto, cada unidade de ensino elaborou um quadro com critérios avaliativos e uma legenda que apontava onde os(as) estudantes precisariam melhorar. Logo, os boletins perderam seu significado histórico de um documento que aponta os que fracassam e os que triunfam. 
A rádio-escola foi implementada em algumas unidades de ensino; fazia parte das discussões referentes ao eixo temático Comunicação. Para a Comissão de Educação as escolas do FMMC precisavam construir alternativas de comunicação interna entre pais, educadores, estudantes e funcionários. Nesta direção, a rádio-escola foi uma idéia que estimulou a criatividade dos(as) estudantes, que precisavam planejar os programas na hora do recreio ou ainda organizar repertórios musicais de acordo com as características culturais de sua comunidade. Nas unidades de ensino onde os grêmios estudantis estavam mais bem estruturados, elaboraram-se também boletins informativos e jornais artesanais.

As bibliotecas de pelo menos quatro escolas do FMMC tiveram auxílio técnico de educadores e estagiários do curso de Biblioteconomia da UFSC. Todo o layout obedeceu a formatação das bibliotecas acadêmicas, ou seja, a correta disposição das prateleiras, a organização dos livros por áreas disciplinares, assim como a arrumação de mesas e cadeiras que facilitassem a rotina de estudos das crianças e jovens. Porém, ainda que recebêssemos este auxílio técnico, fundamental sem dúvida, Santa Catarina não possui bibliotecários(as) escolares, até porque não está previsto concurso público para esta área na educação básica. Assim, quem acaba assumindo tal função são os educadores remanejados, que estão afastados da sala de aula por motivo de doença crônica. Na maioria das vezes são profissionais que não possuem qualquer tipo de vínculo com a biblioteca escolar, sendo raras as visitas a este ambiente tão importante de estudos.

Já a mostra de educação ambiental faz parte do calendário do FMMC há pelo menos quatro anos. Ela acontece na semana do meio ambiente, no mês de junho. Todas as escolas participam, com trabalhos de pesquisa, imagens acerca da situação das encostas dos morros, do sistema precário de esgoto e, principalmente, da falta sistemática de água, sobretudo no verão. O pacto das águas, geralmente coordenado por Vilson Groh, tem ganhado uma importância política cada vez maior em Florianópolis, tendo em vista a possibilidade concreta de privatização da água no município. Isto acarretaria sérias dificuldades para a população empobrecida dos morros.

Contudo, ainda que pese a importância destas ações pedagógicas no interior das escolas do FMMC, nem todas ocorrem satisfatoriamente e, simultaneamente, nestas unidades de ensino. Há escolas que, simplesmente, não acatam as orientações do FMMC e continuam avaliando seu alunado de forma excludente e autoritária, correndo inclusive o risco de serem desligadas do Fórum. O processo de eleição direta para diretores é mais um problema. Há determinados diretores que não vêem com bons olhos o processo democrático de eleição direta por todos os segmentos da escola (pais, estudantes, funcionários e educadores). Tal posição traz um grande desgaste para a Comissão de Educação, que, em vez de se fortalecer, acaba tendo de enfrentar uma queda de braço com seus pares e com a Secretaria de Educação, esta última decididamente contrária ao processo de eleição direta.

Também seria precoce afirmarmos que o FMMC conseguiu romper com a estrutura disciplinar do currículo. Em todas as escolas há a permanência da 
estrutura curricular por disciplinas. Porém três escolas do FMMC já iniciaram a reformulação da 'grade curricular', a partir da pedagogia de projetos e da autonomia discente, tendo como referência a Escola da Ponte, ${ }^{18}$ em Portugal. Estas escolas realizam encontros quinzenais, onde se formalizou um grupo de estudos denominado GTEC/FMMC (Grupo de Trabalho Estudos do Currículo, do Fórum do Maciço do Morro da Cruz).

A ementa de estudos do grupo está alicerçada nos seguintes aspectos: a) concepções de currículo; b) a nova sociologia e a teoria crítica do currículo; c) a teoria curricular e os aspectos da ideologia, cultura e poder; d) currículo e identidade social: o currículo oculto e o manifesto; e) currículo e cultura: relações inter-étnicas, gênero, diversidade cultural e sexualidade; f) currículo e os ritos de exclusão; g) currículo e o uso de tecnologias na produção do conhecimento e a mídia; h) o currículo oficial: PCNs, algumas propostas curriculares estaduais e municipais; i) currículo e PPP. Até o momento, fizemos a discussão do bloco introdutório, tendo como referencial o teórico crítico Michael Apple.

Por ser um GT ainda incipiente, o que se espera desses estudos é a articulação do currículo nas escolas que estão presentes nos encontros, isto é, educadores que possam ser interlocutores nas discussões e articuladores dessa proposta curricular em suas unidades de ensino. Assim, temos experiências-piloto em três escolas, o que deverá facilitar o aprimoramento da construção curricular do FMMC no seu ponto de partida e desdobramentos subseqüentes. Numa delas, um grupo de educadoras das séries iniciais do ensino fundamental realiza um trabalho em conjunto no atendimento a quatro turmas de duas séries diferentes; para tanto, modificou-se o espaço físico, paredes foram derrubadas, ampliando espaços em função da nova dinâmica pedagógica (o chamado 'salão'). Uma vez por mês quatro educadoras-tutoras realizam uma avaliação das principais dificuldades encontradas pelos estudantes no 'salão'; nestes momentos, as turmas ficam em separado com a respectiva tutora.

Nas duas outras escolas o trabalho pedagógico é realizado a partir de temas escolhidos pelos próprios estudantes e vão sendo trabalhados em diferentes disciplinas (caráter multidisciplinar). Um dos projetos desencadeou estudos e discussões propositivas, encaminhadas inclusive ao Fórum do Plano Diretor de Florianópolis. Um outro tema mobilizou a escola durante todo o ano letivo de 2006 em torno do estudo da africanidade. O referido projeto - denominado Malungo - iniciou-se com o trabalho de uma educadora com uma turma de séries iniciais, 'contagiando' toda a escola em função da temática supracitada nas áreas de Língua Portuguesa, Artes, Matemática, Ciências, Educação Física, História e Geografia. Houve saídas de campo, oficinas de máscaras africanas, socialização dos conhecimentos da culinária típica dos afrodescendentes e a realização de um documentário com toda a experiência construída. O projeto teve apoio institucional de três empresas estatais e foi apresentado nas dependências da UFSC na semana da consciência negra, na segunda quinzena de novembro.

Por fim, guardados os limites de uma experiência social tão rica, entendemos que a construção curricular do FMMC está em franca ascensão.

\footnotetext{
${ }^{18}$ Escola da Ponte, localizada em Portugal, cujo articulador pedagógico, professor José Pacheco, tem visitado escolas públicas de Florianópolis a convite da Universidade Federal de Santa Catarina (UFSC).
} 
A formação continuada dos educadores e o compromisso com o processo democrático, ainda que sejam demorados, com resultados nem sempre satisfatórios, são os principais alicerces da permanência do Fórum como articulador privilegiado entre a sociedade civil e a sociedade política. Dar visibilidade às comunidades periféricas em Florianópolis e uma condição de escolaridade com melhor qualidade são as metas permanentes do FMMC.

\section{Referências bibliográficas}

ABRAMOVAY, Miriam (Coord.). Escolas inovadoras: experiências bem-sucedidas em escolas públicas. Brasília: Unesco, 2003.

ARAÚJO, Camilo Buss. A sociedade sem exclusão do Padre Vilson Groh: a construção dos movimentos sociais na comunidade do Mont Serrat. Florianópolis: Insular, 2004.

CAVALCANTI, Helenilda. O desencontro do ser e do lugar: a migração para São Paulo. In: BURITY, Joanildo A. (Org.). Cultura e identidade: perspectivas interdisciplinares. Rio de Janeiro: DPGA, 2002.

COPPETE, Maria Conceição. Janelas abertas: uma experiência de educação no morro Mont Serrat - Florianópolis. São Paulo: Secretariado Interprovincial Marista, 2003.

CORAZZA, Sandra. O que quer um currículo?-pesquisas pós-críticas em educação. 3. ed. Petrópolis: Vozes, 2004.

DANTAS, Jéferson. Plano diretor participativo em risco (?). A Notícia, Joinville/SC, p. 3, 31 out. 2006.

A construção curricular transdisciplinar nas escolas pertencentes ao Fórum do Maciço. Movimento, práticas do cotidiano escolar, São José, n. 4, p. 18-25, set. 2003.

Competências e habilidades na formação dos professores das séries iniciais de nível médio em Santa Catarina: uma análise no interior das Leis 5.692/71 e 9.394/96. Florianópolis, 2002, 170 f. Dissertação (Mestrado em Educação). Universidade Federal de Santa Catarina.

ELIAS, Norbert; SCOTSON, John L. Os estabelecidos e os outsiders: sociologia das relações de poder a partir de uma pequena comunidade. Trad. Vera Ribeiro. Rio de Janeiro: Zahar, 2000.

FERRARO, Alceu Ravanello. Diagnóstico da escolarização no Brasil. Revista Brasileira de Educação, São Paulo, n. 12, p. 22-47, set./dez. 1999. 
FÓRUM DO MACIÇO DO MORRO DA CRUZ (FMMC). Ata ordinária do encontro de Comissão de Educação do Fórum do Maciço do Morro da Cruz. Florianópolis, 23 ago. 2004.

FOUCAULT, Michel. A ordem do discurso: aula inaugural no Collége de France, pronunciada em 2 de dezembro de 1970. 10. ed. Trad. Laura Fraga de Almeida Sampaio. São Paulo: Loyola, 2004.

GHIRALDELLI Jr., Paulo. A quarta República. In: História da Educação. 2. ed. São Paulo: Cortez, 1994.

GIESE, Bárbara. 1964 através da imprensa catarinense: a modernização da agricultura de Santa Catarina enquanto reflexo do ideário do Estado autoritário. In: DIAS, José de Souza (Org.). Santa Catarina em perspectiva: os anos do golpe. Petrópolis: Vozes, 1989.

GROH, Vilson. As comunidades: planejamento e formação da consciência coletiva. Movimento, práticas do cotidiano escolar, São José, n. 2, p. 810, mar. 2003.

. Redes e parcerias: uma proposta que pode chegar às salas de aula. Movimento, práticas do cotidiano escolar, Florianópolis, n. 1, p. 712, set./nov. 2002.

HERNÁNDEZ, Fernando. Transgressão e mudança na educação: os projetos de trabalho. Trad. Jussara Haubert Rodrigues. Porto Alegre: Artmed, 1998.

HOFFMANN, Jussara. Avaliar para promover: as setas do caminho. Porto Alegre: Mediação, 2001.

KLUWE, Razieri Berti. Análise e ações para o desenvolvimento de Boiteuxburgo. Disponível em: < http://teses.eps.ufsc.br/defesa/pdf/ 12695.pdf>. Acesso em 20 dez. 2006.

LINHARES, Célia Frazão; GARCIA, Regina Leite (Orgs.). Michael Apple. In: . Dilemas de um final de século: o que pensam os intelectuais.

São Paulo: Cortez, 1996.

LOPES, Alice Casimiro. Discursos nas políticas de currículo. Currículo sem fronteiras, v. 6, n. 2, p. 33-52, jul./dez. 2006.

NASCIMENTO, Carla D'Lourdes do. "Sagrado dever é servir à Pátria"a educação cívico-patriótica na Série Fontes. Florianópolis, 2003. 158 f. Dissertação (Mestrado em Educação) - Universidade Federal de Santa Catarina.

REIS, Carlos Eduardo dos. História social e ensino. Chapecó: Argos, 2001. 
SAVIANI, Dermeval. Pedagogia histórico-crítica: primeiras aproximações. 7. ed. Campinas: Autores Associados, 2000a.

Da nova LDB ao novo Plano Nacional de Educação: por uma outra política educacional. 3. ed. Campinas: Autores Associados, 2000b. 6,6 MIL casas estão em situação de risco. AN capital, Florianópolis, p. 5, 1 set. 2006 .

SILVA, Tomaz Tadeu da. Documentos de identidade: uma introdução às teorias do currículo. 2. ed. Belo Horizonte: Autêntica, 2003.

VALLE, Ione Ribeiro. Burocratização da educação: um estudo sobre o Conselho Estadual de Educação do Estado de Santa Catarina. Florianópolis: EDUFSC, 1996.

VASCONCELOS, Ruth. O narcisismo e a violência na atualidade. In: BURITY, Joanildo A. (Org.). Cultura e identidade: perspectivas interdisciplinares. Rio de Janeiro: DPGA, 2002.

VARGAS, Diogo. Dignidade pode vencer criminalidade: projetos desenvolvidos na periferia da Capital dão oportunidades e esperança aos jovens. AN Capital, Florianópolis, p. 8-9, 26 mar. 2006.

VIANA, Natália. Universidades farão raio-X de escolas: estudo científico vai permitir análise concreta da situação em comunidades carentes do Maciço do Morro da Cruz. AN capital, Florianópolis, p. 8-9, 18 ago. 2006.

Jéferson Silveira Dantas, mestre em Educação pela Universidade Federal de Santa Catarina (UFSC), é pesquisador do Grupo Interdisciplinar de Estudos da Linguagem (Giel), articulador do GTEC/FMMC e professor efetivo da rede municipal de ensino de São José/SC, na qual ministra a disciplina de História.

clioinsone@gmail.com

Recebido em 16 de junho de 2006.

Aprovado em 18 de janeiro de 2007. 